\title{
Os multiletramentos na educação do/no campo: uma leitura interdisciplinar do trabalho docente
}

\author{
Multiletraments in education of the field: an interdisciplinary reading of teaching work
}

\author{
Marta Divina Pereira da Silva* \\ Universidade de Brasilia \\ Brasília, Distrito Federal, Brasil \\ Rosineide Magalhães de Sousa** \\ Universidade de Brasilia \\ Brasília, Distrito Federal, Brasil
}

\begin{abstract}
Resumo: Este trabalho tem como objetivo observar como professoras de língua materna articulam o ensino ao caráter interdisciplinar. Utilizou-se como instrumento de pesquisa o questionário investigativo para coleta de dados e compreensão, no discurso das professoras, se as práticas em sala de aula estavam relacionadas aos aspectos sociolinguísticos. O aporte teórico para triangulação de dados foi a Análise do Discurso Crítica, o Letramento e a Sociolinguística. Desta forma, compreendeu-se o quão é necessária a pesquisa de campo para o reconhecimento da realidade no espaço escolar e como os docentes veem a prática e os resultados obtidos no ensino da língua materna.
\end{abstract}

Palavras-chave: Sociolinguística. Análise do discurso crítica. Letramento.

\begin{abstract}
This paper has as objective to observe how teachers of mother language articulate education and interdisciplinary. We used as a tool to search the investigative questionnaire for data collection and understanding, in the discourse of teachers, wether the practices in the classroom were related to sociolinguistic aspects. The theoretical contribution to data triangulation was Critical Discourse Analysis, Literacy and Sociolinguistics. It was understood how much field research is necessary for the recognition of reality in the school space and how teachers see the practice and results obtained in the teaching of mother language.
\end{abstract}

Keywords: Sociolinguistics. Critical discourse analysis. Literacy.

\section{INTRODUÇÃO}

É importante propiciar um diálogo entre as abordagens da sociolinguística, do letramento e da análise do discurso crítica, uma vez que a perspectiva de trabalho com a sociolinguística envolve o reconhecimento da existência da variedade linguística e da

\footnotetext{
${ }^{*}$ Mestranda do Programa de Pós-Graduação em Linguística - PPGL - Universidade de Brasília, Brasília, Distrito Federal, Brasil. E-mail: martalinguas@hotmail.com.br.

${ }^{* *}$ Professora do Programa de Pós-Graduação em Linguística - PPGL - Universidade de Brasilia, Brasília, Distrito Federal, Brasil. E-mail: rosemaga@uol.com.br.
} 
diversidade de conhecimentos do sujeito. Este objeto de estudo se encontra dentro do contexto da prática discursiva, para uma análise das relações entre as práticas sociais dos envolvidos no processo de ensino-aprendizagem e para se observar a relação docente com os aspectos culturais que permeiam o trabalho interdisciplinar, sob a perspectiva dos letramentos múltiplos.

Os professores das escolas do/no campo possuem um ambiente de trabalho que nos instiga a conhecer como ocorre o processo de ensino-aprendizagem interdisciplinar em um espaço culturalmente diverso, tanto em termos de língua quanto de conhecimentos e reconhecimentos de mundo, pois, como afirma Street $(2014$, p. 31), "pessoas não são tábuas rasas, à espera da marca inaugural do letramento...", é preciso conceber a diversidade social, cultural e linguística no contexto da sala de aula.

Desta forma, constitui-se uma discussão e análise de dados posterior à aplicação de um questionário composto de questões abertas, com vistas a compreender no contexto da educação do/no campo como o professor rege a interdisciplinaridade em sala de aula. Através do olhar de um pesquisador participante com foco qualitativo (BORTONIRICARDO, 2008), pediu-se que os professores de Língua Portuguesa e Redação da escola aqui denominada "Liberdade", localizada na zona rural de Barreiras-BA, discorressem sobre formação, teoria e didática utilizadas em sala de aula para o desenvolvimento da interdisciplinaridade com o objetivo de reconhecer os letramentos múltiplos e a diversidade linguística.

Para estabelecer uma triangulação de dados, uniram-se as teorias da Sociolinguística, do letramento e da análise do discurso crítica. Desta forma, foram observados os quesitos que abordaram as práticas dos professores em sala de aula, associando os instrumentos à didática para dialogar com o discurso empregado pelos professores de Língua Portuguesa e Produção Textual.

Ademais, verificou-se o quanto é necessária a investigação da prática docente no que diz respeito ao trabalho interdisciplinar, com vistas ao reconhecimento do sujeito como ser participante do processo de ensino-aprendizagem e crítico diante das situações que permeiam a realidade sociocultural em que está inserido.

\section{REVISÃO DA LITERATURA}

As perspectivas atuais para ensino da língua materna direcionam um olhar para o contexto sociocultural de cada sujeito dentro da sala de aula, uma vez que as práticas discursivas individuais trazem consigo marcas das vivências sociais, culturais e linguísticas do indivíduo. Desta forma, é importante a compreensão de como o docente concebe o trabalho com o ensino de língua materna e de produção textual.

E para que se possa compreender esse diálogo é necessário observar como o docente enxerga sua prática em sala de aula, pois, segundo Bortoni-Ricardo (2008, p. 46), "o professor pesquisador não se vê apenas como um usuário de conhecimento produzido por outros pesquisadores, mas se propõe também a produzir conhecimentos sobre seus problemas profissionais, de forma a melhorar sua prática”. 
Desta forma, é notória a importância da autoavaliação docente em relação à sua prática, para compreender seus métodos, instrumentos e teorias até então utilizadas e reavaliar seu próprio discurso enquanto educador. Em muitos casos, os professores materializam um único discurso como sendo imutável, o que os faz não conhecer nem reconhecer as inovações que surgem no processo de ensino-aprendizagem.

A partir do momento em que são compreendidas e reavaliadas as atitudes até então cristalizadas, o professor constrói um olhar de pesquisador e compreende também a diversidade existente dentro do espaço de sala de aula, o que nos direciona aos aspectos linguísticos, sociais e culturais. De acordo com a sociolinguística,

Os alunos que não receberem avaliação de seus professores quanto ao que falaram ou escreveram, respeitando (ou não) os preceitos gramaticais consagrados e louvados no Brasil, estarão sujeitos a críticas e estigma social. Têm os professores, portanto, de ficar alerta à produção linguística de seus alunos em sala de aula promovendo os ajustes necessários, de forma sempre muito respeitosa, nos termos de uma pedagogia culturalmente sensível. (BORTONI-RICARDO, 2004, p. 159)

Há de se observar a importância de o professor considerar os fatores de diversidade linguística dentro da sala de aula, o que não implica deixar de trabalhar os conceitos gramaticais, mas sim saber lidar com as diferenças ou variações linguísticas de seus alunos.

Seguindo a diversidade linguística, é necessário compreender que o docente lida com contextos sociodiscursivos distintos. Cada produção concretizada em sala de aula é oriunda de outras produções já existentes, relacionadas à vivência de cada aluno. Uma vez que Fairclough (2016, p. 93-94) sugere que "a prática discursiva envolve processos de produção, distribuição e consumo textual”, ocorre que a natureza desses processos varia entre diferentes tipos de discurso de acordo com os fatores sociais e como o sujeito se relaciona com tais fatores.

Portanto é necessário um certo manejo no ensino da língua materna e da produção textual, haja vista que a linguagem é um mecanismo que impõe poder, gerando tanto a inclusão quanto a exclusão, no processo de ensino-aprendizagem. Já que a linguagem pode constituir-se como uma ferramenta capaz de bloquear o acesso ao poder e à aquisição de conhecimentos relevantes à produção de mensagens.

Primeiramente, é necessário compreender que letramento envolve muitas outras práticas, além da alfabetização, e é função de todos os professores, independentemente da área de conhecimento, prolongando por toda a vida durante o percurso de formação do sujeito.

Além disso, o letramento está agregado a aspectos de cultura e prática social, ou seja, aspectos socioculturais. Desta forma, cabe aos professores compreenderem que a representação significativa de um texto implica a observação da bagagem cultural diversificada de seus alunos. Cabe, então, um olhar sobre a diversidade e a pluralidade e os aspectos interdisciplinares, pois letrar envolve as diversas áreas do conhecimento. É preciso compreender que interdisciplinaridade é uma prática que envolve todo um grupo de professores em um dado contexto de ensino e aprendizagem. Como reforça Fazenda 
(2013, p. 27), "a interdisciplinaridade pode ser compreendida como sendo uma troca, de reciprocidade entre as disciplinas ou ciências - ou melhor, de áreas do conhecimento".

No que diz respeito à educação do/no campo, o professor deve observar as diversidades consideradas acima como fatores norteadores do planejamento de suas atividades, pois, segundo Pires (2012, p. 43), "o conhecimento e o reconhecimento, o resgate, o respeito e a afirmação da diversidade sociocultural dos povos do campo são fundamentais".

Alinhando os três eixos, é possível observar a necessidade de constante aperfeiçoamento e busca de novas leituras, uma vez que reconhecer as diversidades sociodiscursivas, sociolinguísticas e os letramentos múltiplos requer também a aceitação do outro como sujeito pertencente à prática de produção dentro do contexto da sala de aula. Conforme diz Street (2014, p. 41), "todos na sociedade exibem alguma dificuldade de letramento em alguns contextos".

\section{PRESSUPOSTOS METODOLÓGICOS}

A escolha do método de pesquisa qualitativa para a abordagem desta pesquisa ocorreu em virtude da proposta inicial que permeia o diálogo entre a Sociolinguística, a Análise do Discurso Crítica e o Letramento. Um estudo que prime pela prática docente e sua visão diante dos sujeitos envolvidos no contexto de aprendizagem envolve as relações das práticas discursivas dentro do contexto de aprendizagem.

Esta escolha possibilitou uma discussão mais abrangente das marcas discursivas, sociais, culturais e linguísticas presentes nas respostas de duas professoras do sexto ao nono ano do ensino fundamental II. Como instrumento de geração de dados optou-se pelo questionário, construído a partir de questões abertas, "como a técnica de investigação composta por um número mais ou menos elevado de questões apresentadas por escrito às pessoas, tendo por objetivo o conhecimento de opiniões, crenças, sentimentos, interesses, expectativas, situações vivenciadas etc.” (GIL, 1999, p. 128).

Em seguida à aplicação do questionário, foram realizadas a análise e a discussão dos dados gerados com a finalidade de situar as respostas colhidas no contexto sociocultural dos sujeitos envolvidos na pesquisa.

\section{ANÁLISE E DISCUSSÃO DOS RESULTADOS}

Com o propósito de estabelecer um diálogo entre a sociolinguística, a análise do discurso crítica e o letramento, buscou-se operacionalizar a pesquisa a partir da distribuição de um questionário com nove questões para serem respondidas por duas professoras de uma escola do campo da cidade de Barreiras, região oeste da Bahia. As docentes serão aqui representadas pelos pseudônimos de Sol e Terra, tendo em vista o contexto de trabalho e o objetivo da pesquisa.

A partir destas questões foi possível compreender como a interdisciplinaridade no trabalho com as disciplinas de Língua Portuguesa e Redação é reconhecida pelas docentes. 
Verificou-se, também, como as docentes articulam a interdisciplinaridade no contexto na educação do/no campo.

A primeira questão apresentada abordou o tempo de serviço de cada professora em sala de aula, com a finalidade de traçar um parâmetro de experiência docente e vivência em sala de aula.

P1

Há quanto tempo exerce a docência?

R1

Professora Sol: Há dezenove anos.

Professora Terra: Há vinte e três anos.

A professora Sol respondeu que atua em sala de aula há dezenove anos, enquanto Terra atua há vinte e três anos. No que concerne ao tempo, apresenta-se uma diferença pouco significativa de trabalho entre as professoras, ambas possuem um tempo de experiência considerável em sala de aula.

Em seguida, foi questionado acerca da formação, se possuíam nível superior e a área em que haviam se formado, elemento norteador para os aportes iniciais da pesquisa. É importante destacar que cada disciplina possui seu grau de dificuldade e linha teórica específica para o planejamento das aulas.

P2

Possui nível superior? Qual a formação?

R2

Professora Sol: Sim. Letras e Normal Superior.

Professora Terra: Sim. Pedagogia e História (licenciatura plena).

As professoras responderam ao quesito formação e relacionaram as respectivas áreas. Sol possui formação em Letras e Normal Superior, não especificando a habilitação obtida no curso de Letras. Terra, por sua vez, cursou Pedagogia e História com licenciatura plena.

Percebe-se, com as respostas, que, apesar de possuírem ensino superior, uma das docentes está habilitada para a disciplina de História e não de Letras, o que não é impedimento para atuação no ensino de língua materna, mas pode influenciar na prática docente.

P3

Possui especialização? Em qual área?

R3

Professora Sol: Sim. Em Psicopedagogia e Gestão Escolar.

Professora Terra: Sim. Em História. 
Quanto à formação, Sol e Terra são especialistas, sendo que a primeira, apesar de ter formação em Letras, é especialista apenas na segunda área de formação, neste caso, o Normal superior. A professora Terra, por sua vez, possui especialização na segunda área de formação, demonstrando neste quesito formação na área inicial.

O quarto item a ser observado diz respeito à área de atuação das docentes. Questionou-se, então, em quais disciplinas as referidas professoras ministram aulas, com a finalidade de nestes quatro itens relacionar a experiência, a formação, a especialização e a área de atuação.

\section{P4}

Em qual ou quais disciplinas ministra aulas?

R4

Professora Sol: Artes, Redação, Língua Portuguesa, Ensino Religioso.

Professora Terra: Língua Portuguesa ( $6^{\circ}$ ano), História $\left(6^{\circ}, 7^{\circ}, 8^{\circ}\right.$ e $9^{\circ}$ anos), Geografia ( $6^{\circ}$ ano $)$ e Ensino Religioso ( $8^{\circ}$ ano).

$4^{\circ}$ ano - série inicial (fundamental I)

No quarto item analisado foi possível constatar alguns pontos que traçam divergências entre a formação e a atuação das professoras. Aqui é visto que há uma diversidade de referentes para o planejamento e o desenvolvimento das aulas. Em um primeiro momento tem-se Sol, professora com formação em Letras e Normal Superior, atuando com as disciplinas de Artes, Redação, Língua Portuguesa e Ensino Religioso. A seguir, Terra, com formação em Pedagogia e História, ministra aulas nas disciplinas de Língua Portuguesa, História, Geografia e Ensino Religioso, Terra destacou as séries em que ministra aulas e, além do ensino fundamental II, atua no $4^{\circ}$ ano do ensino fundamental I.

Ao concluir a fase inicial da pesquisa, procede-se à triangulação dos eixos propostos no objetivo desta pesquisa. Para tal, seguem as cinco questões que dialogam entre as abordagens sugeridas. E, para alavancar a discussão, foi questionado às docentes como elas definiriam o ensino de produção textual, e ambas construíram um discurso explicando seu método de trabalho.

P5

Como você definiria o ensino de produção textual? Explique.

R5

Professora Sol: Como um processo que envolve grandes responsabilidades onde a maior delas é a utilização das ferramentas necessárias para que as crianças utilizem a linguagem escrita em sua completude e concretude. Para isso o professor precisa ser mediador e preparado para trazer a compreensão e reflexão dos gêneros a fim de formar escritores capazes de expressar pela escrita suas intenções, sentimentos, necessidade tornando-se autônomo da sua produção. 
Professora Terra: O ensino de produção textual é a compreensão e valorização do uso da escrita com diferentes funções e utilização de diferentes gêneros para trabalhar as variedades linguísticas apropriadas às situações de produção e de circulação.

Cabe nesta questão uma análise mais detalhada da resposta apresentada por cada uma das professoras. No primeiro momento, Sol explana que o ensino de produção textual requer responsabilidades, e que a maior delas seria a utilização das "ferramentas", estas fariam com que as crianças utilizassem a escrita em sua "completude". Quais seriam as ferramentas de que trata a professora Sol para desenvolver essas habilidades? E como seria essa completude e concretude da escrita?

Com tais afirmações, a docente, com sua expressão acerca do uso da língua, ratifica o quão a linguagem pode expressar e significar um mecanismo de poder, no diz respeito à sua utilização. Será que existe realmente essa tal concretude e completude? Há de se verificar o quão é importante o contexto sociocultural para o trabalho em sala de aula, o cuidado com as diferenças demarcadas pela sociolinguística e,

na sala de aula, como em qualquer outro domínio social, encontramos grande variação no uso da língua, mesmo na linguagem da professora que, por exercer um papel social de ascendência sobre seus alunos, está submetida a regras mais rigorosas no seu comportamento verbal e não verbal. (BORTONI-RICARDO, 2004, p. 25)

$\mathrm{Na}$ resposta da professora Terra observa-se outra perspectiva em torno da produção textual, relacionando o contexto das práticas discursivas e da diversidade linguística. Desta forma, estabelece uma relação entre as práticas discursivas de seus alunos e o ensino da produção textual.

Em observância à produção textual, as docentes demonstram valorização da escrita na prática de sala de aula, mesmo que não façam referência à produção oral dos alunos. No entanto, somente a professora Terra coloca em destaque os aspectos da diversidade e do contexto de produção. Vale ressaltar a interação por meio das práticas do letramento que se entrelaçam através das disciplinas em que ambas atuam, bem como a interdisciplinaridade.

Seguindo as concepções de ensino, foi questionado como as docentes definiriam o ensino de Língua Portuguesa. E, a partir desta questão, observou-se em determinados momentos a carga de preconceito presente em partes do discurso apresentado.

P6

Como você definiria o ensino de Língua Portuguesa? Explique.

R6

Professora Sol: Como uma disciplina que requer muitas atividades, principalmente se as crianças e/ou adolescentes não vivenciaram círculos sociais mais cultos (perto de escritores e leitores assíduos), uma vez que o processo de alfabetização não é um processo baseado em memorização, mas em um seguimento no qual o aluno, para aprender a ler e escrever, precisa construir um conhecimento de natureza conceitual, 
ele precisa entender não só o que a escrita representa, mas também de que forma e a representa graficamente.

Professora Terra: O ensino da Língua Portuguesa está baseado no estudo gramatical, no estudo literário e também no estudo das variedades linguísticas, uma vez que o universo linguístico do ser humano passou a ser respeitado e a linguagem passou a ser vista como um elemento de comunicação.

É importante destacar que as marcas discursivas direcionam as cargas de preconceito linguístico, talvez por não conseguirem relacionar os conceitos que lhes são apresentados durante a formação. As duas professoras deixam marcas que elucidam a importância da separação de conteúdo dentro do ensino da Língua Portuguesa.

No entanto Terra demonstra certo cuidado ao mencionar a linguagem como elemento de comunicação, apesar de sempre haver sido um meio de comunicação, ela, a linguagem, passa a ser valorizada após o surgimento de linhas de estudo acerca de seu uso, em termos, a linguística e a sociolinguística.

Para a atuação do professor, é importante que ele tenha reconhecimento da diversidade linguística, respeite-a e tenha manejo no contexto da sala de aula. Com isso, é possível reconhecer que a prática com essa pluralidade deve ser desenvolvida com cuidado e respeito ao outro, mas não se pode deixar de proporcionar a esse outro o aprendizado do conhecimento gramatical.

O sétimo quesito tratou de três itens a serem conceituados pelas docentes. Conforme seus conhecimentos prévios, elas escreveram sobre interdisciplinaridade, letramento e multiletramento, o que propiciou o registro da teoria e da prática em sala de aula relacionadas aos temas em discussão.

P7

Para você, o que é:

a) Interdisciplinaridade:

Professora Sol: É a relação entre duas ou mais disciplinas que podem abranger os mesmos conteúdos e assim aprofundar o conhecimento e dinamizar o ensino.

Professora Terra: É o processo de união de uma disciplina com outras, visando o conhecimento de forma dinâmica.

b) Letramento:

Professora Sol: É o resultado da ação de ensinar e aprender a ler e escrever. É o processo de ensino/aprendizagem. Letrar é mais que alfabetizar.

Professora Terra: É o uso social da linguagem. É aquilo que o ser humano aprende em suas práticas sociais.

c) Multiletramentos:

Professora Sol: É o ato que envolve a leitura articulada em diferentes modalidades de linguagens além da escrita. As mudanças sociais e tecnológicas atuais ampliam e diversificam o trabalho do professor.

Professora Terra: São diferentes tipos de leitura em diversas situações em que o ser humano relaciona o seu conhecimento de mundo com os outros, enfim, são todas 
práticas sociais que englobam as modalidades oral e escrita da língua e também todos os recursos de comunicação.

No que diz respeito ao aspecto interdisciplinar, Sol e Terra apresentaram um discurso direcionando a prática interdisciplinar a uma relação entre disciplinas. No entanto Sol destaca a interdisciplinaridade como sendo a relação do mesmo conteúdo em disciplinas distintas, enquanto Terra menciona o aspecto de dinamizar a aula associando uma disciplina a outras.

A interdisciplinaridade está relacionada com uma prática, um fazer, e, durante todo o processo de planejamento até o desenvolvimento da aula, o docente deve ser interdisciplinar. Em muitos casos, os professores associam à mera relação de conteúdo, no entanto, "ser interdisciplinar" é alçar voos mais altos e mostrar ao aluno, por exemplo, durante uma aula de produção textual, discussões sobre violência e feminicídio, abordando questões sociais e históricas como parte daquela aula. Desta forma, o aluno perceberá, sem a intervenção direta do professor, aspectos de outras áreas de conhecimento, e ele mesmo trará exemplos para afirmar essa percepção.

Já, quando questionadas acerca do letramento, as professoras apresentaram respostas em um discurso marcado por contradições. Verifica-se em Sol um entendimento parcial em termos do que seja letramento: a docente reduz em um primeiro momento ao ato de ensinar a ler e escrever, mas coloca em final de fala que letrar é mais que alfabetizar.

Por outro lado, a professora Terra nos aproxima do letramento no aspecto social, dentro das práticas discursivas. Apropriando-se dos conceitos de letramento como prática social, Sol apresenta em seu discurso, mesmo que de forma breve, uma introdução à diversidade de práticas relacionadas ao letramento, letramentos múltiplos e multiletramentos.

Para finalizar a sétima questão, as docentes conceituaram multiletramentos. Ambas relacionaram a visão multifacetada de leituras de um mesmo texto, embora não soubessem desenvolver as relações temáticas e trouxeram para este conceito uma base plural de reconhecimento do texto.

O conceito de multiletramento - é bom enfatizar - aponta para dois tipos específicos e importantes de multiplicidade presentes em nossas sociedades, principalmente urbanas, na contemporaneidade: uma multiplicidade cultural das populações e a multiplicidade semiótica de constituição dos textos por meio dos quais ela se informa e se comunica. (ROJO; MOURA, 2012, p. 13)

Desta forma, cabe destacar a importância de proporcionar aos docentes uma formação continuada que os propicie um reconhecimento/conhecimento mais amplo de conceitos e termos, até então tratados como "pano de fundo" ou como recortes em palestras proferidas durante as semanas pedagógicas.

A oitava proposta a ser desenvolvida percorreu as práticas das professoras em relação à interdisciplinaridade e aos multiletramentos, como desenvolvem esses eixos durante a aula e a explanação do conteúdo. 
P8

Cite exemplos de como você desenvolve a interdisciplinaridade em sala de aula.

R 8

Professora Sol: Procuro viabilizar um texto em que casam os conteúdos com o maior número de disciplinas. Ex: Chapeuzinho Vermelho. Faço interpretação oral e escrita, dramatizada. Abordo animais domésticos e selvagens, zona urbana e rural, tipos de habitações, cores, importância do amor pela família, perigos das armas, quilometragem, dentro-fora, grande-pequeno e assim por diante.

Professora Terra: Com um determinado conteúdo eu posso abordar várias questões, como as questões linguísticas, sociais, econômicas, históricas, geográficas e artísticas.

Em relação à prática interdisciplinar, as professoras destacaram a abordagem de outras disciplinas associadas às que ministram aulas. Vale ressaltar que tanto Sol como Terra têm uma carga horária preenchida com disciplinas que vão além de sua área de formação. O discurso de Sol apresenta uma exemplificação de como procede com a interdisciplinaridade em sala de aula. Percebe-se, através das marcas do discurso, que, além das turmas do fundamental II, ela ministra aulas no ensino fundamental I.

Após discorrerem sobre interdisciplinaridade, Sol e Terra concluíram o questionário abordando a prática dos multiletramentos em sala de aula. Questionou-se se utilizam os multiletramentos em sala de aula e de que forma utilizavam.

\section{P9}

Você utilizaria os multiletramentos em sala de aula? Como?

R9

Professora Sol: Sim. Procuro não só ensinar o que já sei mas também utilizo ferramentas tecnológicas que me instiguem a produzir e a reproduzir os conhecimentos dos alunos. Isso se torna um pouco mais fácil porque os nossos alunos já são nativos digitais, porém é preocupante, visto que estão também expostos a todo tipo de informação sem questionamentos, sem criticidade de qualidade.

Professora Terra: Sim. Utilizando várias metodologias, como o uso de imagens dos livros didáticos, de músicas e leitura e interpretação de textos variados, além de outros recursos pedagógicos.

Em relação aos multiletramentos, percebe-se que Terra configura o multiletramento como multimodalidade, o que poderia ser mencionado dentro do aspecto do reconhecimento das diversas leituras de um único texto. No entanto cabe destacar a importância de se reconhecer a existência de uma diversidade de linhas de estudo e conhecimento acerca da perspectiva de leitura de um único texto, e que os aspectos multimodais podem nos ajudar na compreensão destes textos.

As marcas presentes no discurso de Sol confirmam que uma educação do campo em uma escola no campo deve primar pelo conhecimento do aluno, principal ator envolvido no processo de ensino-aprendizagem, e de suas relações com a comunidade. 
Neste caso, não poderíamos colocar esse aluno como um "nativo digital", talvez dentro de uma prática de letramento que envolva uma relação com os meios digitais.

É preciso compreender que a linguagem é um instrumento de poder que facilita e/ou bloqueia o processo de ensino-aprendizagem, que estabelece ou cria barreiras que impendem a compreensão de determinados conceitos. Em muitos casos, mesmo sem perceber, o professor cria barreiras entre ele e o aluno, estabelecendo limites de aprendizado.

Cabe destacar que todas as respostas apresentadas possuem marcas de elucidação dos eixos a serem observados. Com isso, foi possível perceber que as professoras compreendem, mesmo que sem aprofundamento teórico, as abordagens propostas nesta pesquisa, possibilitando a observação de suas relações teóricas com a prática em sala de aula para o ensino de Língua Portuguesa e de Redação. Mas, mesmo destacando um breve conhecimento sobre a diversidade das práticas sociodiscursivas e a pluralidade de aprendizado, há um entrave no que diz respeito ao ensino da língua materna e da produção textual levando-se em conta os diversos contextos das práticas discursivas.

\section{CONSIDERAÇÕES FINAIS}

O ensino de língua materna e de produção textual deve ser reconhecido como uma prática em que interaja a vertente da interdisciplinaridade, tendo em vista os aspectos dos multiletramentos na escola, uma vez que o discurso do respeito à diversidade envolve também as relações de reconhecimento das demais ciências e saberes. Para tanto, é importante reconhecer como acontece essa prática no contexto da sala de aula, e isso foi possível através da análise das respostas apresentadas por duas professoras de uma escola do campo, da cidade de Barreiras, região oeste da Bahia.

Além da percepção da relação de ensino das disciplinas em destaque, foi possível perceber que a prática das docentes envolve o aspecto interdisciplinar, visto que ministram aulas em disciplinas que não fazem parte de sua formação. A discussão aqui iniciada abre uma janela, quem sabe até mesmo uma porta, para que haja uma abordagem de maior profundidade, com o intuito de compreender como os professores de língua materna das escolas públicas brasileiras concebem a prática interdisciplinar entrelaçada aos aspectos da pluralidade de conhecimentos com as práticas discursivas e da diversidade social e linguística de seus alunos.

\section{REFERÊNCIAS}

BORTONI-RICARDO, Stella Maris. Educação em língua materna: a sociolinguística em sala de aula. $1^{a}$ ed. São Paulo: Parábola, 2004.

2008. . O professor pesquisador: introdução à pesquisa qualitativa. $1^{\text {a }}$ ed. São Paulo: Parábola,

FAIRCLOUGH, Norman. Discurso e mudança social. $2^{\mathrm{a}}$ ed. Brasília: Editora da UnB, 2016. FAZENDA, Ivani. Práticas interdisciplinares na escola. 13a ed. São Paulo: Cortez, 2013. GIL, Antônio Carlos. Métodos e técnicas de pesquisa social. 5a ed. São Paulo: Atlas, 1999. 
